\title{
Editorial: Why a New Journal?
}

\author{
Scott Edward Highhouse \\ Bowling Green State University
}

Follow this and additional works at: https://scholarworks.bgsu.edu/pad

Part of the Human Resources Management Commons, Industrial and Organizational Psychology Commons, and the Other Psychology Commons

How does access to this work benefit you? Let us know!

\section{Recommended Citation}

Highhouse, Scott Edward (2015) "Editorial: Why a New Journal?," Personnel Assessment and Decisions: Number 1 : Iss. 1 , Article 1.

DOI: https://doi.org/10.25035/pad.2015.001

Available at: https://scholarworks.bgsu.edu/pad/vol1/iss1/1

This Editorial is brought to you for free and open access by the Journals at ScholarWorks@BGSU. It has been accepted for inclusion in Personnel Assessment and Decisions by an authorized editor of ScholarWorks@BGSU. 


\title{
Editorial: Why a NeW Journal?
}

\author{
Scott Highhouse
}

Bowling Green State University

The introduction of Personnel Assessment and Decisions (PAD) is based on the belief that publishing empirical research in industrial-organizational psychology must become quicker and leaner, while also reducing the exponentially increasing workload for board members and ad hoc reviewers. It is also founded on the belief that we need a journal that publishes research that advances the field, and is of interest to both scientists and practitioners. PAD will continually strive to publish groundbreaking and interesting research - not research that simply survives methodological scrutiny (Lynch et al. 2012; Rozin, 2009). The open-access format enables practitioners and international scholars to download research articles at will. The format also eliminates the prohibitive costs associated with traditional journals. There are no costs to readers or authors.

\section{SHORTER ARTICLES}

As I have noted elsewhere (Highhouse, 2014), short reports of empirical research are often an indication that a science has matured (Park, 2009; Taylor, 2009), and shorter articles garner scientific influence more efficiently than standard articles (Haslam, 2010). While journals throughout the sciences have moved to shorter and more accessible formats, I-O journals seem to be going in the other direction (Cucina \& Moriarty, 2015). Too often theoretical framing of articles is a "tactic" to make arguments superficially persuasive (Schaubroeck, 2013). Motivating hypotheses requires reason and logic grounded in the existing literature.

Basic research in personnel psychology has been on-going for over 100 years, creating enough shared assumptions to make tedious introductions and (especially) discussions unnecessary. This is why articles submitted to PAD cannot exceed 4,000 words (exceptions for meta-analyses) excluding references. This model is consistent with those used successfully in journals from other areas of psychology (e.g., Social Psychological and Personality Science).

\section{MODIFIED REVIEW PROCESS}

I certainly recognize that the editor has little influence over what gets submitted. I do, however, believe that the review process can be modified to encourage high quality submissions. I, along with an associate editor, evaluate whether an article should be sent out for review. If one of the two editors judge that it may constitute an important contribution, it will be sent out for review. If both editors have reservations about the contribution, the manuscript will be returned without further review. This process benefits the author, by providing quick turnaround on a manuscript, and reduces the burden on the peer-review system (Cooper, 2009).

When an article is sent out for review, our reviewers are asked to keep the following points in mind:

- At least for the initial review, we prefer shorter reviews to longer ones.

- Write efficient reviews that focus on the major issues, concerns, and improvements.

- Should a revision be invited, reviewers may engage in more micro-analysis.

- The article should make clear the practical contribution and utilize an accessible writing style.

\section{SPECIAL SECTION ON MEASUREMENT AND MEASURES}

Applied psychology has been at the vanguard of measurement theory. Yet, there are few outlets for validity studies, replications, and reports of psychometric issues. Many I-O psychologists currently send their work of this kind to journals seen by only a minority of their relevant audience. The focus of this section is on scale development and refinement, construct validity evidence, and theoretical and applied problems of psychological measurement. This section has a separate editor, Dennis Doverspike, who has created an even more practitioner-friendly section entitled "Practitioner Demonstration Projects."

\section{BAD TIMING?}

We are introducing this journal at a time when researchers are being asked to prove themselves innocent of faking data, HARKING ${ }^{1}$, and selectively reporting research results. The proposed solutions to these alleged problems in our field involve writing longer explanations of methods and more extensive reporting of results, providing research plans in advance of collecting data, and doing more replica-

1 Hypothesize after results are known. 
tions. These solutions seem incongruous with our focus on short and stimulating articles, which will be reviewed with concise comments.

We are certainly concerned with publishing high-quality research, and all submissions are made in compliance with our ethics policy statement. I believe, however, that we may be over-reacting to a few high-profile cases of data fraud. The research submission and review process must contain a certain level of trust from both parties. For instance, there is nothing to keep an author from collecting data from students and saying that the data were collected from executives. And, there is no post hoc screening method for detecting this type of deception.

\section{WHY THE "NARROW" FOCUS?}

Some people have asked me why we did not introduce this open-access journal as a journal of I-O psychology (in general). I envision open-access journals developing much like cable television developed--we have a golf channel, a food channel, a home improvement channel, a cartoon channel, and so forth. I am certainly not advocating the development of so many niche journals that no one is reading outside of their own tiny island. It will be necessary to find the right balance of focus without being too limiting (e.g., open-access journal of work attitudes). Submissions to PAD will determine the breadth of the journal's content, and we view assessment broadly to include many aspects of personnel decision making.

\section{FINAL REMARKS}

This journal will not succeed unless we get high-quality submissions. At this point, I can not promise a high impact factor with which to impress your department colleagues. I can promise, however, high visibility among your relevant constituency - including those who do not have ready access to a library's journal database. The publishing landscape is changing rapidly, and the old rules will evolve and morph. I plan to aggressively promote the journal through social media and other creative methods. Getting your work in front of people who care will be the ultimate impact factor. I will do my best to make sure that happens.

\section{REFERENCES}

Cooper, M.L. (2009). Problems, pitfalls, and promise in the peer-review process. Perspectives on Psychological Science, 4, 84-90.

Cucina, J.M., \& Moriarty, K.O. (2015, July). A Historical Look at Theory in Industrial-Organizational Psychology Journals. The Industrial-Organizational Psychologist, 53, http://www.siop.org/tip/.
Haslam, N. (2010). Bite-size science: Relative impact of short article formats. Perspectives on Psychological Science, 5, 263-264.

Highhouse, S. (2014, January). Do We Need All These Words? The Need for New Publishing Norms in $1-\mathrm{O}$ Psychology, The Industrial Organizational Psychologist, 51, 83-84.

Lynch, J.G., et al. (2012). Knowledge creation in consumer research: Multiple routes, multiple criteria. Journal of Consumer Psychology, 22, 473-485.

Park, D.C. (2009). Publishing in the psychological sciences: Enhancing journal impact while decreasing author fatigue. Perspectives on Psychological Science, 4, 36-37.

Rozin, P. (2009). What kind of empirical research should we publish, fund, and reward? Perspectives on Psychological Science, 4, 435-439.

Schaubroeck, J. M. (2013). Pitfalls of appropriating prestigious theories to frame conceptual arguments. Organizational Psychology Review, 3(1), 86-97.

Taylor, S.E. (2009). Publishing in scientific journals: We're not just talking to ourselves anymore. Perspectives on Psychological Science, 4, 38-39. 